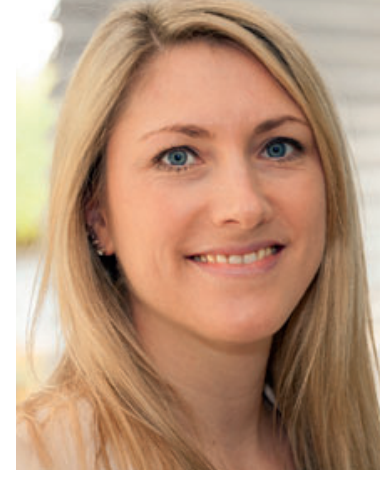

ergopraxis | Editorial

Simone Gritsch

Inhaltliche Leitung ergopraxis

simone.gritsch@thieme.de

\title{
Kind sein dürfen
}

Wenn mein Kollege, ein dreifacher Vater, von Gesprächen mit anderen Eltern erzählt, versteht er oft die Welt nicht mehr. Viele seien stets darauf bedacht, es den Kleinen möglichst einfach zu machen. Misserfolge sollen erst gar nicht entstehen. „Ist das richtig?“, fragt er. „Sollten sich Kinder nicht ausprobieren können und eigene Lösungen finden?“ Und dann erzählt er von Fußballturnieren, bei denen weder Tore gezählt noch Ranglisten erstellt werden. Niemand soll verlieren und traurig nach Hause gehen.

Zugegeben. Ich war früher auch nicht begeistert, bei den Bundesjugendspielen immer nur eine Urkunde zu bekommen. Gerne hätte ich auch mal eine Sieger- oder gar Ehrenurkunde in den Händen gehalten. Aber war es nicht toll, sich herausgefordert zu fühlen? Und gibt es im Leben nicht noch viele Rückschläge, mit denen man umgehen muss?

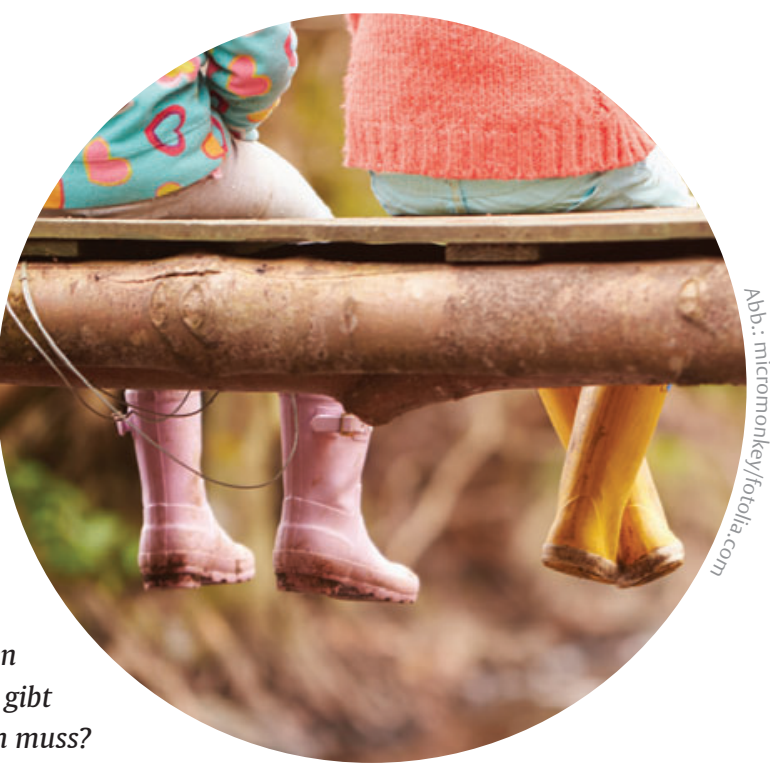

Wie sich auch Freizeitprogramm und Spielverhalten der Kinder über die letzten Jahrzehnte verändert haben, zeigt Marlis Schauers Artikel ab Seite 18. Dabei habe ich mich gerne an meine eigene Kindheit erinnert. Ich wuchs auf dem Dorf auf und wusste genau, bei welchen Nachbarn es immer etwas zu essen gab, wessen Haustiere ich streicheln konnte und auf welchem Erdhaufen der nahe gelegenen keltischen Ausgrabungsstätte man immer noch ein paar Knochen und Scherben fand.

Heute werden viele Kinder mit dem Auto zur Schule gefahren, abgeholt und zum straff durchorganisierten Nachmittagsprogramm weiterkutschiert. Ich war stolz darauf, alleine bzw. mit einer Freundin den Schulweg zu gehen und genoss die Freiheit, mich hin und wieder in einen Hinterhof zu verziehen, um ungestört die Hausaufgaben abzuschreiben. Oder klammheimlich auf dem Nachhauseweg einen Abstecher in die Süßigkeitenabteilung des Dorfkiosks zu machen.

Wie viel Struktur von Erwachsenen brauchen Kinder also tatsächlich, um ihre Potenziale zu entwickeln und Gestalter ihres eigenen Lebens werden zu können? Die Antwort von Hirnforscher Prof. Dr. Gerald Hüther lesen Sie auf Seite 21.

Ihre

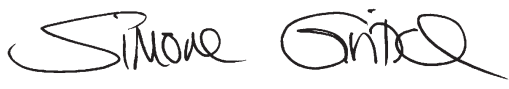

